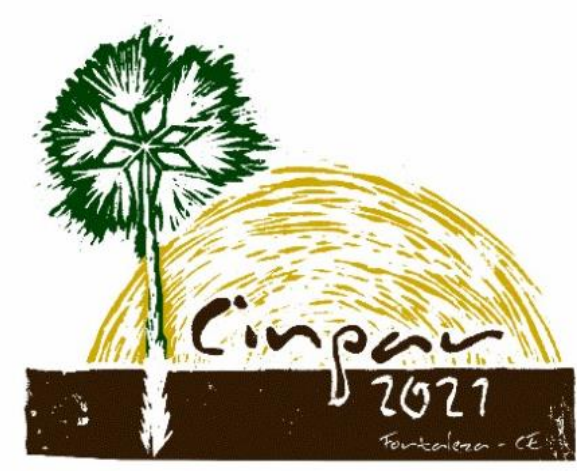

XVII Congresso Internacional sobre Patologia e Reabilitação das Construções

XVII Congreso Internacional sobre Patología y Rehabilitación de las Construcciones

XVII International Conference on Pathology and Constructions Rehabilitation

FORTALEZA (Brasil), 3 a 5 de junho de 2021

https://doi.org/10.4322/CINPAR.2021.083

\title{
Análises de causas de manifestações patológicas em áreas comuns e fachadas de condomínios residenciais verticais: uma revisão.
}

\section{Analysis of causes of pathological manifestations in common areas and facades of residential condominiums: a review.}

\author{
Yan Lucas e Silva VASCONCELOS ${ }^{1}$, Monike Hellen Loiola VASCONCELOS ${ }^{2}$, Gustavo Araújo VASCONCELOS ${ }^{3}$, \\ Mikaell Gustavo Farias GOMES ${ }^{4}$, Ortência Gabriela Gomes CARVALHO ${ }^{5}$, Rita Gabrielly Sampaio PEREIRA ${ }^{6}$

\footnotetext{
${ }^{1}$ Faculdade Luciano Feijão, Sobral, Brasil, yanlucasvasc@gmail.com

${ }^{2}$ Faculdade Luciano Feijão, Sobral, Brasil, monike.loiola@yahoo.com.br

${ }^{4}$ Faculdade Luciano Feijão, Sobral, Brasil, mikaelgfg@gmail.com

${ }^{5}$ Faculdade Luciano Feijão, Sobral, Brasil, ortenciagabriela@hotmail.com

${ }^{6}$ Faculdade Luciano Feijão, Sobral, Brasil, gabysampaio819@gmail.com
} \\ ${ }^{3}$ Faculdade Luciano Feijão, Sobral, Brasil, eng.gustavovaas@outlook.com
}

Resumo: Para atender demandas e expectativas de consumidores e usuários, obras edificadas devem obedecer a quesitos de segurança, desempenho e conservação adequados. Contrapondo-se a isso, cenários de inobservância aos requisitos de projeto, uso de materiais de baixa qualidade e falta de manutenção preventiva e corretiva favorecem o aparecimento de manifestações patológicas. Em edificações que abrigam várias unidades habitacionais, essa situação pode ser ainda mais severa, devido ao adensamento populacional desses ambientes, o que pode intensificar o uso e desfavorecer diferentes aspectos de conservação. Nesse contexto, o estudo de manifestações patológicas vem se tornando promissor, devido à possibilidade de identificá-las precocemente e gerar possibilidades de uma melhor gestão da edificação, evitando prejuízos aos usuários. Relativamente a condomínios residenciais verticais, por exemplo, estudos têm sido incentivados nessa área, por abrigarem grande número de pessoas, e, em alguns casos, também constituírem habitações de interesse social. O estudo ora proposto buscou realizar um levantamento bibliográfico a fim de identificar as manifestações patológicas mais comuns em condomínios verticais multifamiliares, buscando também compreender os mecanismos atuantes nas principais causas identificadas relativas a essas manifestações. Para isso, serão utilizados repositórios mais comuns em Engenharias I, determinados conjuntos de palavras-chave para a busca, excluídos arquivos duplicados e tabulados os principais resultados sobre manifestações em fachadas. Os resultados permitiram evidenciar que, para esse tipo de edificação, as manifestações mais comuns se relaciona às fases de projeto e de execução. Ainda foi constatado que um forte contributo à evolução dos problemas encontrados foi a inexistência, em sua totalidade, de rotinas de manutenção.

Palavras-chave: Manifestações patológicas, Edificações verticais multifamiliares, revisão.

Abstract: In order to meet the demands and expectations of consumers and users, built works must comply with requirements for adequate safety, performance and conservation. In contrast to this, scenarios of noncompliance with the design requirements, use of low quality materials and lack of preventive and corrective maintenance favor the appearance of pathological manifestations. In buildings that house several housing units, this situation can be even more severe, due to the population density of these environments, which can intensify the use and disadvantage different aspects of conservation. In this context, the study of pathological manifestations has become promising, due to the possibility of identifying them early and 
generating possibilities for better management of the building, avoiding losses to users. Regarding vertical residential condominiums, for example, studies have been encouraged in this area, as they house a large number of people, and, in some cases, also constitute social housing. The study now proposed sought to carry out a bibliographical survey in order to identify the most common pathological manifestations in vertical multifamily condominiums, also seeking to understand the mechanisms acting on the main identified causes related to these manifestations. For this purpose, the most common repositories in "Engenharias I" will be used, certain sets of keywords for the search, duplicate files will be excluded and the main results on manifestations in facades will be tabulated. The results evidenced that, for this type of building, the most common manifestations are related to the design and execution phases. It was also found that a strong contribution to the evolution of the problems encountered was the lack of maintenance routines in their entirety.

Keywords: Pathological manifestations, vertical multifamily buildings, bibliographic review.

\section{Introdução}

O crescimento acelerado da indústria da construção civil nos últimos anos, possibilitado pelos incentivos de crédito do governo federal para construções de diversas finalidades e motivado pelo adensamento populacional e pela verticalização urbana, abriu espaço para o desenvolvimento de novas técnicas e novos materiais relacionados aos sistemas de revestimentos e fachadas (MACEDO E MACHADO, 2019). Mesmo com esse desenvolvimento, não foi possível impedir a deterioração, muitas vezes precoce, das estruturas, ocorrência de acidentes e, consequentemente, perdas de desempenho, falhas involuntárias e problemas relacionados à imperícia (MACEDO E MACHADO, 2019; SOUZA E RIPPER, 1998).

Diante desse cenário, mesmo com tecnologias e materiais inovadores disponíveis, Pontes Júnior e Barbosa (2019) afirmam que ainda é possível observar o crescimento do número de incidências de manifestações patológicas sobre, principalmente, revestimentos e fachadas. Ainda adicionam que, relacionadas a isso, estão causas como omissão de etapas e elementos construtivos, execução inadequada e desrespeito às especificações de projeto. Como consequência disso, tem-se a redução do desempenho de fachadas e desvalorização estética e econômica do equipamento edificado.

Obras edificadas devem atender às demandas e expectativas dos consumidores e favorecerem questões de segurança, apresentando um desempenho adequado. Essas obras tem vida útil determinada, a qual pode variar a depender de condições como qualidade do material empregado na execução e existência de rotinas de manutenção periódicas. Falta de manutenção aliada às causas descritas podem favorecer o surgimento de manifestações, que caso não sanadas, podem evoluir para cenários onerosos e que geram riscos aos usuários. Diante disso, destaca-se a importância de estudos de patologias das construções, compreendendo as relações das manifestações com suas possíveis causas.

Qualquer estrutura edificada possui um tempo de vida útil em relação aos seus elementos estruturais, como pilares e vigas, e construtivos, como tijolo, chapisco, emboço, argamassa colante, revestimento cerâmico. Esses processos de redução de vida útil podem ser naturais e decorrentes do uso e tem como consequência a diminuição do desempenho para o qual foram projetadas. Para que isso seja respeitado, é necessário que existam rotinas de manutenções corretivas e preventivas durante o tempo de utilização. Nesse sentido, temse como consequência a necessidade de reparos, que acarretam custos, mas garantem a segurança daqueles que dela fazem uso (MARÇAL e AMARAL, 2019).

Além dos aspectos estéticos e de segurança, é válido destacar que as edificações podem constituir importante patrimônio histórico de uma nação, também devendo ser preservadas. A conservação desses bens, históricos ou não, devem contar com ciclos de manutenção orientados para a prevenção e/ou correção de patologias prediais, considerando a complexidade e heterogeneidade dos diferentes sistemas construtivos (CARVALHO, 2016).

Considerando todos esses fatores, adiciona-se ainda a necessidade de conservação dos recursos naturais e econômicos relacionados à capacidade de edificar, tanto em empreendimentos recentes quanto nos reparos necessários àqueles que manifestam algum dano (CBIC, 2013 apud ZUCHETTI, 2015). 
O estudo do tema baseou-se na recorrência de manifestações patológicas em edificações residenciais multifamiliares, em nível nacional (PONTES JUNIOR E BARBOSA, 2019; LIMA 2015), principalmente em fachadas, o que pode contribuir para uma desvalorização estética e econômica da edificação, destacando-se como tema de importância.

Com base nesse contexto, é evidente a demanda de estudos relacionados às principais causas de patologias em edificações, auxiliando na capacitação de profissionais e contribuindo para a prevenção desses problemas recorrentes (BAUER et al, 2015). Para os autores, "existe a necessidade de estudos com enfoque mais detalhados que permitam quantificar outras variáveis que influenciam nos processos de degradação [das fachadas], tais como: as condições ambientais, a orientação cardeal e o nível de gravidade e a localização dos danos." Isso pode ajudar a garantir a conservação, segurança e estética de elementos estruturais e construtivos, contribuindo para uma valorização global das estruturas edificadas.

Além disso, as investigações aqui procedidas podem ajudar a gerar material que contribua para uma futura prevenção do surgimento dessas patologias, garantindo a conservação, segurança e estética dos elementos construtivos e estruturais e favorecendo a qualidade de vida e sensação de segurança dos usuários.

Com relação à hipótese motivadora, a escrita baseou-se na investigação bibliográfica: "As principais causas de manifestações patológicas em fachadas e áreas comuns de edificações residenciais multifamiliares verticais estão relacionadas às fases de projeto, construtiva e de utilização/manutenção da edificação".

Frente à possibilidade de degradação estética e desvalorização econômica, é importante que sejam compreendidos os mecanismos de interação entre os agentes causadores das manifestações patológicas e os elementos de fachadas e de áreas comuns a fim de que sejam melhor estudados. Isso pode favorecer diagnósticos mais fidedignos, reduzir a subjetividade no processo e facilitar a aplicação de rotinas de manutenção mais efetivas. Além disso, a criação ou reunião de dados de patologias prediais podem favorecer o desenvolvimento de ferramentas ou tecnologias que auxiliem na correlação dos dados com sua causa, auxiliando no aprimoramento, por exemplo, de técnicas de inspeção predial. Neste sentido, este trabalho busca reunir informações sobre as manifestações patológicas mais comuns em condomínios verticais, esclarecendo problemas recorrentes nas diferentes regiões do país, através de uma revisão bibliográfica. Nesta abordagem, também se buscou chamar atenção para a responsabilidade profissional relacionada às principais causas.

\section{Objetivos}

\subsection{Objetivo geral}

Este estudo visou identificar as manifestações patológicas recorrentes em fachadas e áreas comuns de condomínios verticais, através de uma revisão bibliográfica, buscando compreender os mecanismos atuantes nas principais causas das manifestações patológicas identificadas.

\subsection{Objetivos específicos}

Como objetivos específicos, pretendeu-se:

- Efetuar um levantamento teórico para embasamento do tema manifestações patológicas em unidades habitacionais;

- Coletar dados e identificar as principais manifestações patológicas em blocos habitacionais em condomínios residenciais verticais;

- Determinar as manifestações mais comuns dentro do montante de trabalhos reunidos;

- Identificar as causas das manifestações patológicas. 


\section{Metodologia}

O estudo foi baseado em uma investigação teórica sobre as principais causas de manifestações patológicas em fachadas e áreas comuns de edificações multifamiliares verticais, onde foram confrontados diversos autores e suas perspectivas sobre $o$ assunto.

Segundo Gil (2008), a pesquisa ora proposta ainda pode ser classificada quanto aos procedimentos técnicos e objetivos envolvidos. Fundamentalmente, quanto aos procedimentos técnicos, a pesquisa será bibliográfica, com consulta de material já elaborado e consolidado em livros e artigos. Quanto aos objetivos, a pesquisa também terá cunho exploratório, para um primeiro contato dos autores com o tema; será descritiva, buscando descrever os mecanismos envolvidos nas causas das manifestações patológicas; e também explicativa, ao relacionar a causa ao tipo de manifestação observada.

Para a aquisição do material bibliográfico, foram utilizados buscadores de periódicos, como Portal de Periódicos Capes e Science Direct. A busca também foi complementada por uma varredura no Google acerca do tema, a fim de identificar trabalhos não depositados nos buscadores especializados. Foram utilizadas palavras-chaves como "manifestações patológicas em edifícios", "patologias", "fachadas", "condomínios" e semelhantes, em conjunto ou não e avaliados os resultados segundo os objetivos da pesquisa.

\section{Resultados e discussões}

Rodrigues (2013) fez um levantamento em 10 edificações verticalizadas de diferentes configurações sob responsabilidade de uma construtora em Porto Alegre. Entre os empreendimentos analisados, quatro tiveram número de ocorrências consideráveis ( de 134 a 233). Este comportamento, para a maioria dos casos, estava relacionado a uma maior área (quanto maior a área total das edificações mais manifestações foram detectadas). Outro fato destacado pela autora foi a idade das edificações, onde as quatro de maior ocorrência possuíam idade não superior a dois anos. A análise temporal das ocorrências deu-se de junho a agosto, período normalmente mais chuvoso do ano. Do montante analisado, defeitos em esquadrias e instalações elétricas e hidráulicas representaram $66 \%$ das ocorrências.

Em relação às esquadrias, a autora esclarece que a falta de vedação dos elementos, o descolamento de guarnições e marcos e a má fixação foram os mais recorrentes e, com isso, podem desencadear nas fachadas e áreas internas uma série de outros problemas. A recorrência de infiltrações estava diretamente ligada às falhas de fixação de peitoris e esquadrias, ocasionando deterioração da pintura e descolamentos na edificação.

No que concerne às tubulações de água quente e fria, o principal problema constatado está ligado a má execução de soldas entre tubos e conexões. Isso fez com que se manifestassem manchas e bolores nas áreas internas e externas das unidades vistoriadas. Essas falhas hidráulicas também foram motrizes para o aparecimento de falhas elétricas, por incompatibilidade entre os projetos e entrada de fluido em pontos elétricos. Das manifestações analisadas, Rodrigues (2013) ainda conclui que, provavelmente, estejam associadas a inadequações de execução.

Monteiro et al. (2013) também executaram uma inspeção criteriosa em 07 edifícios residenciais de Sobral (CE), seguido de consulta aos usuários. Junto à gama de constatações, foram identificadas fissurações e trincamentos em decorrência de movimentações térmicas e mecânicas e, possivelmente, de inadequado fator água/cimento no material de emassamento. Além disso, também foram identificados desplacamentos de revestimento de peças estruturais em decorrência de oxidação de armaduras. Ao cenário avaliado, os autores relacionam a necessidade de manutenção e de projeto e execução mais rigorosamente acompanhados.

Soares e colaboradores (2014) aplicaram uma metodologia focada no usuário para a identificação das patologias em conjuntos habitacionais da região cuiabana. A partir de uma pesquisa de campo, foram aplicados questionários com 15 perguntas de múltipla escolha que visaram o conhecimento dos moradores sobre os cuidados com a edificação e a percepção dos mesmos sobre serviços prestados pela construtora. Como resultado, identificou-se que $90 \%$ dos entrevistados receberam o manual da edificação, mas apenas $25 \%$ deles haviam lido. Do montante, $83 \%$ não sabiam diferenciar o significado de manutenção preventiva e

Análises de causas de manifestações patológicas em condomínios residenciais verticais: uma revisão. 
corretiva, e, mesmo identificando uma série de problemas nas edificações, não sabiam se posicionar. A isso, os outros atribuem o alto índice de não leitura do manual, onde são esclarecidos os termos e indicadas ações a serem tomadas em caso de percepção de falhas ou manifestações patológicas. Dos problemas constatados, a maioria se relacionava às instalações hidráulicas, elétricas e infiltrações. Especificamente em fachadas, as infiltrações deterioram pinturas e revestimentos cerâmicos. Pelos relatos de moradores, os problemas foram percebidos logo após entrega da obra, o que pode indicar a ausência de projetos, não observância ao mesmo ou execução inadequada. Quanto às conclusões, os autores alertam para uma corresponsabilidade, indicando que aquilo que foi constatado precisa ser sanado pela construtora mas também destacando a importância da leitura do manual do usuário da edificação para que rotinas de manutenção preventiva sejam implementadas.

Juliani (2015) utilizou uma abordagem de anamnese para um condomínio residencial de 04 blocos na região de São José (SC) em alvenaria estrutural, próximo ao mar. Com resumo do levantamento nas áreas externas, o estudo indicou fissurações verticais, em paredes, próximo a janelas, junto de peitoris ou ainda na interface alvenaria/laje. Além dessas, foram constatados desprendimentos da tinta do substrato. Como causas das fissurações, podem estar relacionadas às movimentações devido às distribuições de tensões ou variações higroscópicas e térmicas (diferenças de materiais, em alumínio e concreto). Ainda há a presença de molduras nas janelas que podem estar contribuindo para que a água de chuvas, por exemplo, não escoem de maneira adequada, sejam acumuladas e favoreçam a deterioração. As fissurações, algumas escalonadas, diretamente em fachadas, podem estar relacionadas aos recalques de fundações. Como conclusão, a autora relaciona as manifestações às fases de projeto, principalmente, e execução em sua maioria.

Figueiredo e colaboradores (2017) estudaram um prédio do tipo caixão, seguindo as investigações em alvenaria estrutural, na região de Recife. A edificação não possuía pilares ou vigas, era assente sobre estacas raiz, datava de 18 anos à data do estudo e é composta por dois blocos de térreo e mais 04 pavimentos. As manifestações foram identificadas a partir de inspeções visuais, entrevistas com usuários e análises de projetos existentes. De maneira geral, foram identificadas as seguintes manifestações patológicas e a elas atribuídas as causas que seguem: descolamento e destacamento de revestimentos cerâmicos, inclusive das fachadas, devido ao uso de argamassa comum à época da construção; manchas escuras na fachada, atribuídas à falta de manutenção durante a utilização da estrutura, favorecendo a proliferação de fungos; bolhas e destacamentos da pintura em áreas comuns e fachadas, como consequência da água que percola nos revestimentos; fissuras e rachaduras horizontais, devido aos recalques de fundação por ser construída em área de mangue estar sujeita às variações dos níveis de maré; fissuras verticais próximo às juntas de dilatação das fachadas, em decorrência da ausência de manutenção nos 18 anos de existência do prédio; fissurações do revestimento externo em decorrência das variações de temperatura; e, finalmente, abatimento do piso de pátio em função da inexistência de contrapiso e construção nas proximidades de um sistema de fossa. Como interpretação geral, detectou-se a falta de manutenção do edifício e a utilização de métodos de execução inadequados, frente às solicitações do ambiente e da estrutura.

Azolim e colaboradores (2017) avaliaram as fachadas de 12 edificações de um conjunto habitacional em Alegrete (RS). Na inspeção, foram feitas visitas aos locais e confeccionados mapas de localização das patologias identificadas. Bolor e fissurações mapeadas foram constantes nos resultados observados, seguidos de diferentes outros tipos de fissurações (horizontais, verticais, inclinadas). Nas áreas onde o bolor foi constante, constatou-se a presença recorrente de umidade e proteção contra a incidência direta do sol. Às fissurações horizontais, foi atribuído como causa o fato de serem localizadas em zonas de encontro de alvenarias com elementos estruturais. A isso, pode-se atribuir a falta de elementos de junção que absorvam as diferentes movimentações de maneira uniforme. Para a maioria das manifestações, os autores recomendaram reparos simples que poderiam facilmente controlar a evolução dos problemas destacados. Ainda, adicionaram a importância de rotinas de manutenção para que o aspecto visual da edificação não fosse negativamente interferido.

Pontes Júnior e Barbosa (2019), utilizando outra abordagem, analisaram 13 edificações de quatro pavimentos na cidade de Macapá, Amapá, constituintes de um parque residencial. As edificações, de idade aproximada de 05 anos, foram construídas em concreto armado com fechamento em blocos cerâmicos. Entre o padrão de patologias encontrado nas 13 unidades, constatou-se que as fissurações foram de maior ocorrência, seguidos de manchamentos, descascamentos de pinturas e desagregação. De uma maneira geral, a 
localização de cada grupo de manifestações variou para cada bloco, contudo, também foi percebido um padrão de aparecimento em cantos e extremidades, painéis de paredes muito longos e na proximidade de esquadrias, inclusive aquelas com jardineiras. Juntos às esquadrias, relacionaram-se em maior número, fissurações devido à ação da água. Em cantos e extremidades, as fissurações e manchamentos foram mais comuns, o que se pode atribuir às falhas de projeto e problemas com execução. Esse mesmo padrão de aparecimento de manifestações patológicas se repete na região de paredes contínuas, entretanto, os autores atribuíram como principais causas a variação higrotérmica e a deformação lenta das estruturas.

O mesmo estudo ainda explorou uma matriz de correlação para as possíveis causas das manifestações identificadas. Nesta abordagem, a classificação das causas das patologias foram reunidas em quatro grupos: falhas na especificação, falhas no processo executivo, ações de fatores externos e comportamento em uso. No primeiro grupo, falhas na especificação, os autores indicam que a escolha de materiais incompatíveis ou ausência dos mesmos favorecem o aparecimento de manchas, desagregações e descascamentos em pinturas. Além disso, o dimensionamento incorreto de peitoris e a ausência de vergas e contravergas e de pingadeiras estão ligados a fissurações e manchas. No segundo grupo, falhas no processo executivo, a utilização de materiais desconhecidos ou não indicados foram fatores forçantes para fissurações e manchas e a aplicação de materiais desconsiderando a boa prática podem ter contribuído para o aparecimento de desagregações e descascamentos. Em relação aos fatores externos, o aparecimento das manifestações foi afetado pela chuva, umidade, variação térmica, lixiviação de sais e aparecimento de vegetação. No último grupo, o comportamento em uso, os causadores foram a falta de limpeza ou a realização desta com produtos inadequados e as acomodações estruturais.

Como conclusões, percebeu-se fissurações e manchas como patologias de maior ocorrência, em sua maioria, em torno de aberturas, paredes contínuas e extremidades. Muitas dessas manifestações poderiam, segundo os autores, ter sido evitadas em função de um maior rigor técnico em função das especificações de projeto e controle de qualidade nos sistemas de revestimentos das fachadas.

Cabe adicionar o trabalho de Peres (2001), que analisou um prédio histórico unifamiliar na cidade de Pelotas/RS. Embora diferente da abordagem dos outros trabalhos comentados anteriormente, com edificações multifamiliares, o padrão de patologias e suas causas parecem ser recorrentes para os estudos verificados. Na edificação, datada de 1878, recorrem manifestações relacionadas à umidade, fissuras e trincas e descolamentos de revestimentos. Estas recorrências, segundo a autora, se manifestam como consequência da falta de manutenção, de erros de execução ou da utilização de materiais inadequados. Embora seja uma edificação histórica e existam restrições em relação a sua manutenção, evidencia-se esse "posicionamento cultural" em relação ao uso das edificações. Como causa motora, a autora, suportada pelo trabalho de Oliveira et al. (1994), atribui à umidade a origem dos problemas mais frequentes, principalmente na zona externa da edificação, podendo estar relacionada com as condições climáticas da região.

\section{Considerações finais}

Em relação aos trabalhos utilizados, foram levantados 08 estudos de diferentes regiões do país. Do conjunto estudado, foram verificadas manifestações recorrentes, como: ausência de vedação em esquadrias, devido a erros de execução de peitoris e dos caixilhos e posicionamento de elementos, como molduras, sem considerar seus efeitos. Fissurações como consequência de movimentações térmicas e mecânicas também foram identificadas na maioria dos estudos. Essas manifestações podem ser relacionadas a inexistência de juntas de dilatação, ausência de projetos ou má execução de fundações. Infiltrações que causam descolamento de pinturas e revestimentos ou uso de material inadequado também foram percebidos. Ausência de vergas e contra vergas, segundo boas práticas de construção, também foram motrizes para a identificação de fissurações em fachadas. A presença de bolores em alguns dos trabalhos sugere a necessidade de manutenção.

Considera-se, pela análise, que a maioria dos problemas constatados estão relacionados às fases de projeto e execução, de responsabilidade dos técnicos dirigentes e fiscais das obras. Isso pode evidenciar a necessidade de maior atenção técnica quanto à observância de projetos, métodos e profissionais envolvidos na execução, a partir da criação de sistemas de controle de qualidade, por exemplo. 
Outro ponto de destaque é a percepção do usuário, indicando uma co-responsabilidade na conservação da edificação. No trabalho analisado, a maioria dos usuários, embora possuíssem o manual da edificação, não o haviam lido. Mesmo tendo sido avaliado apenas um trabalho e considerações adicionais, como classe social e nível de instrução devam ser melhor estudadas, pontua-se certa negligência quanto às rotinas de manutenção por parte desses usuários/proprietários. Ainda evidencia-se que, embora as tecnologias tendam a avançar, esse posicionamento do usuário é cultural e precisa ser modificado a partir de metodologias de educação.

\section{Referências Bibliográficas}

Azolim, G. E.; Dos Anjos, L. O.; Temp, A. L. (2017). Levantamento de manifestações patológicas em condompinio de edificações no município de Alegrete (RS). XXVIII Congresso Regional de Iniciação Científica e Tecnológica em Engenharia -CRICTE 2017. Ijuí, Brasil; novembro 2017.

Bauer, E.; Castro, E. K.; Silva, M. N. B. (2015). Estimativa da degradação de fachadas com revestimento cerâmico: estudo de caso de edifícios de brasília. Cerâmica, 358 (61), 151-159.

Carvalho, L. Z (2016). Levantamento de manifestações patológicas de edificações do patrimônio cultural do município de Alegrete-RS. Trabalho de Conclusão de Curso, Curso de Engenharia Civil, Universidade Federal do Pampa, Alegrete, Rio Grande do Sul, Brasil.

Figueiredo, A.; Figueiredo, A.; Sousa, N. M.; Nascimento, E. (2017). Manifestações patológicas identificadas em um edifício de alvenaria resistente em Recife (PE). Conferência Nacional de Patologia e Recuperação de estruturas - CONPAR 2017. Recife, Brasil; agosto 2017.

Gil, A. C. (2008). Como elaborar projetos de pesquisa. 4. São Paulo: Atlas.

Juliani, M. A. (2015). Análise de manifestações patológicas em condomínio construído com alvenaria estrutural: estudo de caso. Trabalho de Conclusão de curso, Curso de Engenharia Civil,Universidade Federal de Santa Catarina, Florianópolis, Brasil.

Lima, B. S. (2015). Principais manifestações patológicas em edificações residenciais multifamiliares. Trabalho de conclusão de curso, Curso de Engenharia Civil, Centro de Tecnologia, Universidade Federal de Santa Maria, Santa Maria.

Macedo, C. B; Machado, C. G. K. (2019). Estudo de manifestações patológicas em condomínio residencial horizontal. Cippus, Canoas, 7 (2), 57-72.

Marçal, A. V.; Amaral, D. (2019). Proposta de um plano de inspeção predial em conformidade com a Lei $n^{\circ}$ 2805/2008 do município de Balneário Camboriú/SC. Trabalho de Conclusão de Curso, Curso de Engenharia Civil, Universidade do Sul de Santa Catarina, Balneário Camburiú.

Monteiro, L. M. S. Et al. (2013). Incidência de manifestações patológicas em prédios residenciais em SobralCe. IX Congresso internacional sobre Patologia e Recuperação de Estruturas - CINPAR 2013, João PessoaPB, Brasil; junho 2013.

Peres, R. M. (2001). Levantamento e identificação de manifestações patológicas em prédio histórico - um estudo de caso. Dissertação de mestrado, Escola de Engenharia, Universidade Federal do Rio Grande do Sul, Porto Alegre, Brasil.

Pontes Júnior, A. A. S.; Barbosa, C. F. M. N. (2019). Levantamento de manifestações patológicas em fachadas: estudo de caso de um conjunto de edificações residencias. Trabalho de conclusão de curso, Curso de Engenharia Civil, Departamento de Ciências Exatas e Tecnológicas, Universidade Federal do Amapá, Macapá.

Rodrigues, A. C. (2013). Levantamento das principais manifestações patológicas em edificações residenciais de uma construtora de Porto Alegre. Trabalho de Conclusão de Curso. Escola de Engenharia, Departamento de Engenharia Civil, Universidade do Rio Grande do Sul, Porto Alegre.

SOARES, R. C. Et al. (2014). Verificação de manifestações patológicas em Condomínios residenciais do programa "minha casa, minha Vida" ocasionados por falta de manutenção preventiva da baixada cuiabana. 1ํ. Congresso Brasileiro de Patologias das Construções - ALCONPAT 2013 - Foz do Iguaçu, Paraná, Brasil; maio 2014.

Análises de causas de manifestações patológicas em condomínios residenciais verticais: uma revisão. 
Souza, V. C.; Ripper, T. (1998) Patologia, recuperação e reforço de estruturas de concreto, São Paulo: PINI.

Zuchetti, P. A. B. (2015). Patologias da construção civil: investigação patológica em edifício corporativo de administração pública no Vale do Taquari- RS. Trabalho de conclusão de curso, Curso de Engenharia Civil, Centro Universitário Univates, Lajeado, Rio Grande do Sul, Brasil. 